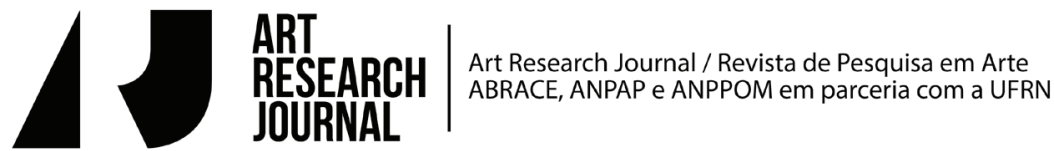

\section{Variações sobre momentos de dança}

Geisha Fontaine

Université Bordeaux Montaigne

Compagnie Mille Plateaux Associés

geisha.fontaine@gmail.com

Tradução para o Português: Cássia Navas

Qu'est-ce que l'immanence? Une vie.

Gilles Deleuze (2003, p. 361)

Noite de junho de 2016, em Paris, na Maison du Japon, Min Tanaka dança'. No começo da performance, dissimula-se por suas roupas e um caleçon mascara sua cabeça, mas o espectador percebe que o corpo do bailarino está vibrando de experiências. O japonês tem 71 anos. Vemos sua idade, mas a esquecemos. No oriente, nas artes do espetáculo, isto acontece muitas vezes. O papel do artista relaciona-se a sua idade, como Zeami o mostra tão bem em seus escritos sobre o Nô.

Em sua performance Locus Solus, Min Tanaka torna intensos três fundamentos da criação em dança: o corpo, o tempo e o espaço. Este artista pensa que a dança "sempre nasce da sociedade de seu tempo", e, é verdade que ela seja determinada espacial e temporalmente. Seu desafio é, no entanto, o de procurar "uma dança sem precedentes, sem nome, ainda nunca vista" ${ }^{2}$. Cada récita de Locus Solus é única, em função do local e do momento em que ela acontece, portando sempre o conjunto de lugares e momentos anteriores.

A dança cria um presente irrigado de uma memória do corpo, aberto à singularidade de

'A performance aconteceu em "Camping", manifestação proposta pelo CND-Centre National de la Danse, à Pantin (direção: Mathilde Monnier).

${ }^{2}$ Apresentação de Locus Focus, por Min Tanaka: http://www.mcjp.fr/fr/la-mcjp/actualites/locus-focus--min-tanaka. 
seu devir. É uma arte do corpo, na qual a noção de tempo é essencial. Em meu livro Les danses du temps, insisti sobre a relação entre o movimento dançado, a finitude do corpo e os desafios coreográficos. O movimento aparece, dura um momento, desaparece. O corpo, ele também, aparece, dura um momento e desaparece. No livro, também desenvolvi ligações entre a estruturação das obras coreográficas e a concepção de tempo de que são testemunhas. "Correntemente, a ideia do tempo é uma questão de adição: 2 e 2 , 3 e 3 ou 2 e 3 como em Stravinsky. Para mim é diferente: no interior deste tempo que se adiciona, há outras diferentes espécies de tempo, com durações onde tudo é possível, vários elementos ou nada ...", dizia Merce Cunningham (1972, p.26). Estes possíveis, aí incluindo-se o "nada", são objetos duma investigação significativa, na qual se visa perceber a realidade de maneira diferente, principalmente a relação entre o espaço e o tempo. A percepção dos ritmos e dos espaços corporais interiores constantemente dialoga com aquela do meio ambiente. A este respeito, o bailarino e pedagogo Jerome Andrews tem uma linda questão do espaço interior: "O espaço interior pode ser dividido entre as pernas, braços, etc., mas, fundamentalmente, é uma questão de tempo internalizado (...) É um longo trabalho de algumas semanas, de alguns meses, de alguns anos. Não temos pressa, nós temos o tempo. Quando alguém corta o fio do tempo, a gente tem o tempo" (Andrews, 2016, p.85).

Neste texto, eu gostaria de seguir com algumas reflexões sobre as interações entre o corpo e o tempo, e insistirei nas relações entre uma época e um corpo que dança ${ }^{3}$, colocando, a cada momento, algumas questões metodológicas.

\section{O corpo, o tempo: transformações e passagens}

Evoquei o projeto de Locus Solus, no início deste texto, porque a forma como ele combina os dados concretos e os desafios coreográficos é, antes de tudo, temporal. Min Tanaka dedica-se, efetivamente tanto aos "começos" como aos "fins" para que entrem em ressonância, para dançar entre tempo e espaço, para aguçar a concentração no momento em que se está atento ao meio ambiente. Esta é uma das características do pensamento oriental, a de não funcionar por pares que se opõem, preferindo a sua aliança. É o mesmo processo que favorece o corpo que dança.

\footnotetext{
${ }^{3}$ De forma diferente, é uma problemática já abordada em meu texto Such a little thing, DanceHouse Diary, \#5, July-October 2013, Australia, p. 3-5.
} 
"Qual corpo? Temos vários", observou Roland Barthes (1975). Os cabelos brancos de Min, seu corpo marcado, são sinais de sua idade. Entretanto, durante a performance, este mesmo corpo torna-se um sinal de várias idades e períodos. Num momento, vemos um jovem, em outro adivinhamos um personagem que surge como duma gravura, ou ainda imaginamos uma criatura da qual duvidamos a existência.

O corpo que dança é o vetor visível, visual, da transformação. É aí que reside sua força artística. É o sinal da passagem do movimento enquanto ele se perfaz. Esta é a sua primeira função, bem antes daquela de ser expressivo. Esta transformação é percebida, mas ela não se deixa capturar. A transformação se transforma, a passagem passa, tais são as vertigens do tempo. O jardim da Maison em que Min dançou em Paris sempre é visível. A dança que ele propôs não o é mais. É essa desaparição que faz do tempo um parâmetro inseparável da própria definição da dança". "Uma representação somente, bem no ponto, isto deve bastar", pensava o escritor Jean Genet, a propósito de sua peça Les Paravents ( 1966, p. 18). "O ator deve agir rapidamente mesmo em sua lentidão, mas a sua velocidade, rápida, surpreenderá (...). Num jogo semelhante fará viver o ator e a peça. Então: aparecer, cintilar, e morrer", Genet acrescentaria (p.48). Mas esta exigência visava marcar o espectador. Se o desaparecimento é uma condição do espetáculo que os franceses costumam nomear de "vivo", isto não significa que nada aconteceu, a memória do acontecido podendo durar muito tempo. Contudo, a duração da lembrança é indissociável como aquela duma vida. Se não for filmado ou descrito, o instante da dança não atravessará os séculos. Esta relação entre memória e esquecimento, entre a duração da obra e vida, redobra, ao mesmo tempo em que interroga, o papel do intérprete na criação coreográfica. Até onde o corpo do bailarino intervém - está envolvido na obra? Frequentemente esta é uma pergunta que faço a respeito de certas peças de Trisha Brown hoje remontadas por jovens bailarinos. Os movimentos são os mesmos que aqueles da estreia, contudo eles não parecem ser os mesmos. Aqui se coloca uma questão para o repertório de dança, para o seu patrimônio ${ }^{5}$. A dimensão

\footnotetext{
${ }^{4}$ Este tema foi amplamente desenvolvido em Les danses du temps, op. cit. Ver, sobretudo: «Moment $1 \gg \mathrm{e}$ «Moment 2».

${ }^{5}$ Há quinze anos na França falava-se, essencialmente, de «repertório» em dança. A partir dai trabaIhamos sobre uma noção de patrimônio, dentro dum contexto sobre o passado que se assemelha àquele encontrado nas artes visuais. Não se trata, certamente, de se limitar à reprise de obras num trabalho sobre o passado. Mas a escolha da palavra é sintomática, por dizer respeito à necessidade constante de legitimação dos atores do campo da dança, principalmente face aos representantes do estado francês, como apoiador, através de subvenções, da cultura.
} 
cultural do corpo do bailarino é um dos fatores que definem a criação, e coreógrafos são mais ou menos conscientes a este respeito. Da mesma forma que a evolução das técnicas mudou a forma de pintar, a mudança da corporeidade influenciou a forma de coreografar. "Tudo é mutável, no conjunto dos fenômenos" (1984, p. 408), constata Emmanuel Kant. Surge, então, a questão do fenômeno. O corpo é tudo salvo um fenômeno único, no sentido filosófico do termo ${ }^{6}$. O corpo é tudo, salvo uma generalização. Mas, certamente, ele é mutável. Há transformações relacionadas ao processo vital, às células, à organicidade, etc. Há também transformações proporcionadas pelos aprendizados e experiências do bailarino. Ao longo de sua carreira, o bailarino, dialeticamente, lida com estes dois modos de transformação. Insisto sobre a dimensão material do corpo porque é ele que a dança trabalha e é nele que a mesma é criada. Não esqueço, entretanto, de toda a atividade cerebral e de suas manifestações menos tangíveis. Igualmente, a dança as trabalha. Existe a plasticidade do corpo, assim como a do cérebro; existe toda uma interdependência entre o corpo e o cérebro - o que a neurociência atesta durante vários anos. Não haveria mesmo como distinguir corpo e cérebro e melhor seria encontrar novos conceitos! Entretanto, insisto no funcionamento do organismo, porque ele tem um caráter de implacabilidade com o qual a dança joga. Queira ou não, envelheço; queria ou não, e até onde sabemos, irei morrer. A dança agrava esta tendência do corpo, oferecendo-Ihe - nada incomuns- atualizações, deslocamentos e velocidades. A dança como liberdade face à lei do tempo. É apenas uma tentativa e, obviamente, não podemos estar certos do que acontecerá. É um risco que se toma, uma aposta a se fazer. No entanto, isto não impede que Min dance aos 71 anos, enquanto outros não o façam ${ }^{7}$. Os coreógrafos, como os bailarinos, multiplicam as durações, este é um dos desafios da sua arte. O corpo é, simultaneamente, lugar de passagem e de memória: ele revela uma época, mas também assinala uma história de práticas de dança. Em The Art of Memory (1966), Frances A. Yates, interroga a história de memorização. Desde a Grécia antiga, e de maneira precisa, ela analisa os elos entre a memória, o lugar e a imagem. Mas seria interessante também pensar o processo de memorização na dança considerando-se o corpo

\footnotetext{
${ }^{6} \mathrm{Na}$ história da filosofia ocidental, o fenômeno é associado às aparências e às percepções. Este conceito refere-se às hierarquias estabelecidas ao longo da história em busca da verdade. Consequentemente, esta noção acentua concepções dualistas amplamente questionadas nos dias de hoje. ${ }^{7}$ O bailarino japonês Kazuo Ohno, por sua vez, dançou até depois dos 90 anos.
} 
como "lugar" duma memória sensível, sublinhando-se a questão do movimento em detrimento da questão da imagem e do espaço.

\section{Os fatos e seus momentos}

Os discursos sobre o corpo e sobre a dança dependem do olhar duma época sobra a outra e do contexto no qual eles são produzidos. Seria necessário trabalhar sobre uma arqueologia do corpo que dança. Na verdade, a história da dança não questiona, suficientemente, como os fatos de uma época são interpretados, descritos e analisados, no momento em que se passam e ulteriormente. Faz falta, à história da dança, uma análise da interpretação dos mecanismos dos eventos. Seria, como fez Foucault, "intensificar-se, o mais possível, a busca de diferenças entre os eventos que parecem formar uma mesma espécie" (Veyne, 2010, p. 45). Esta hermenêutica convém para a dança.

Não sendo uma historiadora ou uma antropóloga, nisso não coloco o desafio de minha pesquisa. Contudo, me parece importante distinguir como os corpos que dançam lidam com as informações do tempo e de como criações coreográficas questionam, ilustram e anunciam algo de nosso tempo. Não se trata de se apegar à uma dimensão social desta ou daquela temática. O desafio é o de decodificar como uma coreografia destaca-se em relação a outras coreografias, mesmo quando ela parece pertencer a um mesmo grupo. É esta diferenciação, esta "diferença" à maneira de Derrida, que permite uma precisão de análise. Para tanto, tomo como exemplo o uso do folclore na coreografia contemporânea. Isso vai me levar a questionar as noções de contemporaneidade e pós-modernidade. Quais são as implicações entre o que aconteceu e o que foi criado? A que necessidades, aí incluindo-se a estética, relaciona-se o uso de tradições na dança contemporânea?

$\mathrm{Na}$ arte, é comum que sejam assumidas as práticas tradicionais. Na dança, o folclore desempenhou um papel inegável no balé romântico, na dança clássica, nos Ballets Russes, na dança moderna, etc. Eterno retorno? Nos anos 2010, as danças tradicionais são convocadas por muitos coreógrafos europeus. Alguns exemplos: Christian Rizzo, com D'après une histoire vraie (2013), Alessandro Sciarroni com FOLK-S Will You Still Love Me Tomorrow? (2013), Gabor Varga e József Trefeli com JINX 103 (2013), Simon Mayer com Sons of Sissy, (2015). 
Já em 2005, em sua obra Magyar Tàncok, Eszter Salamon se remetia às danças tradicionais húngaras, aprendidas em sua infância e, em 2008, Mickaël Phelippeau à dança bretã, no "duplo-retrato" Yves $C^{8}$. Mas é mais nos anos 2010 que numerosos coreógrafos assumem o folclore. Introduzir elementos das artes tradicionais em criações inéditas não é uma inovação. Muitas vezes foi algo que seguiu em paralelo ou um como um pretexto, enquanto que na segunda década do século XXI, esse uso é afirmado e colocado no centro do processo criativo. Por quê? A resposta parece simples. É reconfortante, especialmente para o público. Após a tendência conceitual na qual o movimento torna-se rarefeito, com a proeminência de uma arte que "decepciona", o engajamento físico está de volta. Uma utilização contemporânea da tradição traz também uma referência histórica, preservando-se a necessidade do "novo". Reciclamos, de outra maneira, as danças tradicionais. É uma ação, de alguma maneira, ecológica. Mas, obviamente, tentamos fazê-lo de maneira inovadora.

É necessário analisar esta "reciclagem temporal" de formas antigas e o que ela assinala, em função do uso que dela se faz nesta ou naquela obra. A metodologia consiste em decodificar o que nos seduz porque o reconhecemos, assim como aquilo que nos estimula porque não o reconhecemos. Para fazê-lo, vou me concentrar no Sons of Sissy ${ }^{9}$ de Simon Mayer. Sua obra assim se apresenta:

Quatro bailarinos-músicos utilizam, experimentalmente, a música tradicional dos Alpes, diversas danças grupais e rituais, liberando-as de qualquer regra e conservadorismo. Reinterpretações artísticas e novos significados temporários aí se fundem de forma inesperada. Os Sons of Sissy (Filhos de Sissi) fazem tudo o que podem para honrar seu nome, às vezes como um popular e engraçado quarteto, às vezes como um combo de dança ritual experimental, com um senso de humor que lhes permite romper, radicalmente com tradicionais modelos masculinos ${ }^{10}$.

Durante o espetáculo, passos e notas musicais pertencentes às artes tradicionais são crescentemente deslocadas até se tornarem excessivas, a totalidade funcionando como uma sequência de possíveis transformações e inesperados. Na última

\footnotetext{
${ }^{8}$ No espetáculo bi-portrait Yves $C$, trata-se precisamente da «round», dança local do Finistère Norte, que Mickaël Phelippeau descobriu, há mais de trinta anos atrás, ao reencontrar o coreógrafo de dança tradicional, Yves Calvet, que a praticava desde os três anos de idade.

${ }^{9}$ Os intérpretes são: Matteo Haitzmann, Simon Mayer, Patric Redl e Manuel Wagner.

${ }^{10}$ Ver o site de Simon Mayer: http://simon-mayer.tumblr.com/
} 
parte, os quatro intérpretes ficam nus, invertendo completamente a questão do popular, que assim se oculta, tornando-se irreconhecível. Oscilando entre um recital, quase simpático e extravasamentos corporais frenéticos, o espetáculo está entre um questionamento de gênero e o papel atribuído ao masculino. Tudo acontece com grande humor e, a forma como a como a tradição é usada é, concomitantemente, audaciosa, rascante e agradável. Este desvio associa-se ao forte envolvimento dos corpos, que rompem, de alguma forma, com o folclore, à medida que o levam ao seu limite. A utilização de formas tão referenciais é, com frequência, delicada. Note-se que, no final do século XIX, e no início do século seguinte, as danças tradicionais provenientes de outros países foram muito populares, porque satisfaziam o gosto da época pelo exótico ${ }^{11}$. Em seu livro L'éveil des modernités - une histoire culturelle de la danse (O despertar da modernidade - uma história cultural da dança), Annie Suquet, analisa como esta espécie de mania pelas danças de alhures era ladeada por uma hierarquia que se estabelecia entre "sociedades primitivas" e "sociedades civilizadas". A contrário, é principalmente em sua própria tradição que coreógrafos investem atualmente ${ }^{12}$. Esta atitude poderia corresponder à busca de suas raízes e remeter à identidade para a qual eles contribuam $^{13}$. Na Europa, as danças tradicionais são hoje reivindicadas por partidos de extrema direita que se opõem à criação contemporânea. Podemos questionar o uso, na realidade convencional, de danças tradicionais por certos coreógrafos contemporâneos, propondo formas em que todos podem se reencontrar, garantindo-se, assim, turnês com casas cheias. A abordagem de Simon Mayer é muito diferente; nela ecoa uma preocupação sobre o que estamos observando, sobre uma definição do movimento que estamos vendo. Aqui revemos o "o princípio da singularidade" tão caro a Foucault que lembra que o "envolvimento das formas universais é, ele mesmo, histórico" (1994, p. 580). Igualmente podemos também privilegiar a singularidade do que analisamos sobre a nudez. Como estão os corpos nus, no palco? De que esta nudez é feita? Um corpo nu no teatro do fim da década de 1960: sua função é semelhante àquela dum corpo nu em Sons of Sissy?

\footnotetext{
${ }^{11}$ Ver o capítulo «La fascination des ailleurs». Annie Suquet, 2012.

${ }^{12}$ Nos exemplos citados acima, uma exceção deve ser apontada em Christian Rizzo, que criou sua obra sob a forte impressão de uma curta dança folclórica em Istambul.

${ }^{13}$ Não seria banal uma indagação sobre este «retorno às fontes» na Europa dos anos 2010, em que o acolhimento a inúmeros migrantes provoca, em certos cidadãos, um inégavel retorno a si.
} 


\section{Contemporaneidade, pós-modernismo, pós-modernidade}

A reciclagem das formas anteriores da arte nos remete à noção de pós-modernidade. Ora, delimitar temporalmente tendências artísticas requer especificar-se a área em que nos situamos. Tomemos a categoria "contemporânea". A história contemporânea começa no final do século XVIII, a música contemporânea após a Segunda Guerra Mundial, a arte contemporânea na década de 1960 e a dança contemporânea em meados dos anos 1970. As noções de pós-modernismo e de pós-modernidade ${ }^{14}$ são menos fáceis de se apreender. A dança pós-moderna diz respeito aos anos 1960-1970 e não é em nada comparável à pós-modernidade proposta pelo arquiteto Charles Jencks. A dança pós-moderna coloca as informações da coreografia em posição de tabula rasa, enquanto a arquitetura pós-moderna favorece o ecletismo e a justaposição de formas anteriores sobre as quais se reinveste. Inúmeras propostas coreográficas dos 2010 s poderiam ser comparadas a esta pós-modernidade. A reutilização de materiais coreográficos de séculos passados e de formas populares nunca tinha sido tão próspera. O que a criação coreográfica enuncia? Qual a historicidade que o olhar a ela lançado aponta? Esta é uma questão importante para o trabalho sobre o tempo na dança. Como funcionam as temporalidades que ressoam num dado período? Quais são as ligações e as diferenças entre a criação em dança e pós-modernidade em arte ${ }^{15}$ ? Aqui, qual é a função sensível que se aciona? Qual função crítica está, então, em ação? o que seria um corpo pós-modernista?

Em 1981, o teórico Fredric Jameson preconiza: Always historicize. Esta injunção é duplamente estimulante para a dança. A doxa estipula que a dança sempre está no presente. Certamente a efetivação da dança está no presente, mas este presente é um substrato formado por camadas temporais. Combinar temporalidades é um dos fundamentos da coreografia e do movimento dançado. O improvisador

\footnotetext{
${ }^{14}$ Aqui, não me arriscarei a definir estes dois termos. Segundo os autores, sua diferenciação não converge. Algumas deles os utilizam indiferentemente. Precisar estes conceitos para encontrar o que eles podem acionar no campo da dança será um dos desafios de meus futuros trabalhos.

${ }^{15}$ Como o indicado mais acima, esta noção de "pós-modernidade" necessitaria ser afinada. Na Europa, o termo, por exemplo, é menos utilizado na França do que nos países dos Balcãs. De toda a maneira, é uma noção que gera questões estimulantes, não pelo cuidado relativo a uma sua classificação, mas por fazer pensar em certas mutações, tanto na arte quanto na sociedade.
} 
Steve Paxton recordava, com justeza, que mesmo na improvisação, o bailarino não está somente imerso no presente. Memorização e antecipação são fatores decisivos para aquele que improvisa. Mais especificamente, o improvisador percebe e tem consciência de memórias e de possibilidades, dos "possíveis". Existe a historicidade de cada corpo, de cada criação e de todo discurso contido na dança. Às pesquisas sobre a dança, por vezes, falta perspectiva, provavelmente por causa da necessidade - legítima - de um maior reconhecimento devido a este campo mais teórico. Em trabalhos sobre Rudolf Laban, por exemplo, nem sempre são analisados os contextos de sua pesquisa (mesmo seus sucessores, à procura de alargar suas propostas, atualizando-as, não pensam, suficientemente, nas ligações entre seus enunciados e a época na qual este teórico os elaborou).

Para todo pesquisador de dança, seria conveniente analisar as condições de surgimento do que, em cada período, se pensa como "verdadeiro". Always historicize poderia ser o objetivo tanto da pesquisa quanto da crítica. Isto não significaria ser um historiador, aqui não se coloca este desafio! ${ }^{16}$ Simplesmente é fazer a escolha de se viajar pelos períodos, concentrando-se no que nenhum deles tem de específico. Em seu notável livro sobre o pós-moderno ${ }^{17}$, Fredric Jameson se pergunta sobre a espacialização da arte e da cultura no mundo globalizado. Ao fazê-lo, na tradição da Escola de Frankfurt, ele questiona a indústria cultural e os seus modos de operação. A dança, ela está dentro da indústria cultural? Faz sentido pensar a criação coreográfica como uma forma fractal? Ela é representativa de modos de operação identificáveis de em outros campos, em outras escalas?

A dança contemporânea é uma parte da dança, que é uma parte das artes da cena, que é uma parte da cultura, que é uma parte da atividade humana. Pode-se, portanto, considerar que a dança contemporânea seja um território de ação minoritária, que não é afetado nem pela cultura de massa, nem por objetivos de artes consideradas como maiores. Com isto, podemos pensar que o que está acontecendo na criação coreográfica contemporânea, e no corpo que aí está envolvido, não diz respeito à indústria cultural.

\footnotetext{
${ }^{16}$ Lembremos que Foucault é um filósofo, colocando-nos questões de filosofia, e que, é a partir delas, que aborda a dimensão histórica do que estudou.

${ }^{17}$ Ver: Jameson, 1991. Para este autor: "O mais certo é apreender o conceito do pós-moderno como uma tentativa de pensar o presente historicamente, numa época em que, antes de tudo, esqueceuse de como pensar historicamente."
} 
Não obstante, se forem observados os fatos, verifica-se que esta fissura não é assim tão clara. Nos países ricos, a globalização da arte, incluindo-se a arte coreográfica, é real. Para a dança, é claro que se trata mais de uma escala simbólica do que econômica. A dança contemporânea francesa, por exemplo, é um dos bastiões a se exportar. Convém que se note que isto diz respeito à chamada dança conceitual (Jérôme Bel, em particular), mas também diz respeito a uma dança dita popular (por exemplo, a do coreógrafo de hip-hop Anthony Egéa). No entanto, existe uma ampla gama de outras produções artísticas produzidas na França. Em termos de quantidade, não se trata, estritamente, da indústria cultural, mas do processo de se colocar no mercado. Para voltar ao exemplo acima discutido, a reintrodução de danças tradicionais na criação contemporânea pode contribuir para que algumas companhias possam viajar ao redor do mundo. Poderíamos acreditar nisto de "forma absoluta"18? O estilo trans-histórico, transnacional, igualmente transcendental, que afeta a todos, em toda parte, pelo reconhecimento do que lhe é proposto no "seu" no folclore ${ }^{19}$.

Se pensarmos a partir da mônada de Leibniz, toda criação de dança contemporânea, carrega, potencialmente, algo que tem o nome de "indústria cultural". Isso poderia ser um signo do pós-modernismo. É uma problemática complexa, que se remete à função do corpo. Na Europa, os bailarinos de hoje recebem uma formação que Ihes permite "tudo dançar". Isto ecoa a polivalência a que cada futuro profissional deverá ser capaz. Aptidão para estar em aeroportos iguais onde quer que estejam no mundo, com as mesmas marcas internacionais de produtos das duty free, com os efeitos do jet lag e, o corpo que se adapta ${ }^{20}$. O bailarino contemporâneo é o protótipo perfeito do empregado global dos países ricos, que viaja sem ter tempo para ver o país em que ele dança, provendo sua força máxima de trabalho em cada estadia, retornando depois para casa, sempre à procura de contratos futuros ${ }^{21}$. No entanto, a persistência do "sintoma frac-

\footnotetext{
18"O absoluto não está ao nosso alcance" dizia, no entanto, Foucault. "Se bem que tudo é possivel", acrescentaria Paul Veyne. Foucault, sa pensée, sa personne, op. cit., p. 69. Encontramos, muito frequentemente referências a uma dimensão "imemorial" e "universal" em relação às danças tradicionais, apesar dos trabalhos em antropologia, que se referem, constantemente, a esta "atemporalidade".

${ }^{19} \mathrm{~A}$ criação de Simon Mayer, mais acima evocada, difere deste posicionamento estratégico. Com efeito, o coreógrafo apropria-se de músicas e danças tradicionais, tornando-as excessivas e dissociadas. ${ }^{20}$ Sobre este tema, ver: Hartmut Rosa, Accélération, une critique sociale du temps, Paris: La découverte, 2010.

${ }^{21}$ Por exemplo, na França, a situação econômica dos bailarinos não é a pior entre todas. Em muitos países, muitos deles não são sequer assalariados.
} 
tal" ou da "persistência de Leibniz" não mudará em nada o fato de que os artistas são vistos como privilegiados. Estes novos privilégios podem lhes fazer ir até a Coréia do Sul, onde poderão machucar-se durante uma apresentação ${ }^{22}$.

A indústria cultural também se refere ao campo da dança. Não se faz necessário, todavia, que entremos em generalizações. É preferível, sempre que esta questão esteja em tela, que se pergunte: como, porquê e onde? Isto implica em privilegiar o conteúdo da obra, sua própria matéria e os jogos que ele promove. Como cada coreógrafo compõe com o corpo de cada bailarino? Em que parte do mundo? $\mathrm{O}$ conteúdo de uma criação coreográfica existe, antes de tudo, pelo corpo do que por sua atualização. Que sentido tem este conteúdo?

Jovem, eu fiquei muito impressionada com o filme Saló, de Pier Paolo Pasolini. Inspirado em Sade, as imagens eram ásperas e não era fácil de as assistir. Era cinema. Às vezes, as propostas cênicas tratam da violência para a denunciar, mas às vezes elas são por ela banalizadas. O palco não permite as mesmas "trucagens" que um filme. O conteúdo duma obra não se dissocia da forma como são tratados os corpos. Um bailarino é um artista. Um bailarino é também um trabalhador. Um coreógrafo é também um artista e um trabalhador. A diferença entre os dois é que o coreógrafo decide o conteúdo da obra e a forma como os corpos ali estarão. Mas quais corpos? Os corpos contemporâneos? Os corpos pós-modernos? O corpo que se volta à tradição? Os corpos que buscam autonomia? Os corpos que aderem à proposta do coreógrafo? Os corpos que dela escapam? A textura do movimento, as tonicidades que se privilegiam e as modalidades das relações entre bailarinos são determinantes na composição coreográfica. Os corpos que dançam, eles são matéria de quais escolhas artísticas? São signo de que pensamento de mundo?

Na década de 1970, Merce Cunningham assim descreve sua forma de trabalhar:

Quando nós caminhamos, damos um passo após o outro. Podemos parar ou caminhar, acelerando ou em marcha lenta, e isto nem sempre é igual. Em primeiro lugar, é necessário encontrar a noção física do movimento. Eu começo por aí; depois indico um determinado período de tempo, por exemplo: 10 segundos, durante os quais será executado este movimento; mas nada impede de se fazer uma parte dele um pouco mais rapidamente e uma outra de forma mais

\footnotetext{
${ }^{22}$ Refiro-me aqui ao caso duma bailarina francesa cujo contrato previa duas apresentações por dia durante um longo período. Era uma viagem, seguramente, rentável. Ela se feriu ao final da turnê.
} 
lenta; não é necessário fazer exatamente como eu, desde que todo o movimento dure os 10 segundos (1972, p. 26).

O desejo do coreógrafo é o de fixar uma duração para a qual o bailarino pode trazer algumas mudanças de velocidade para um certo movimento. Para cada um, existe a possibilidade duma variação individual da estrutura fixa. Isto é muito estimulante para o bailarino, que assim pode escolher a distribuição do tempo que the convier. Trinta anos mais tarde, na década de 2000, é no virtuosismo técnico exigido por Cunningham que o bailarino se concentra. Como o testemunha o solo Cédric Andrieux (2009) concebido por Jérôme Bel, em colaboração com Andrieux. A performance física a ser garantida é tamanha, que a meta do intérprete é principalmente conseguir fazer o que tem que fazer. A "dança Cunningham" tornou-se tão complexa que ela requer um compromisso quase esportivo do bailarino. A posição do intérprete difere, assim, daquela dos anos 1970. Mais uma vez, é importante distinguir as diferentes fases da trajetória do coreógrafo e observar as mudanças na sua maneira de trabalhar, em momentos diferentes, com a criação e com os bailarinos. Como coreógrafa, a temática do corpo que dança e, portanto, do bailarino, sempre me preocupa. Em 2015, criei Millibar, une ritournelle chorégraphique em colaboração com Pierre Cottreau. Essa obra, realmente me fez pensar sobre as ligações entre o movimento, o corpo e o momento. Desde 1998, a mesma sequência de dança foi filmada, em Super-8 em todo o mundo ${ }^{23}$.

Esta sequência, que eu danço usando as mesmas roupas, dura quarenta segundos. Pierre Cottreau fez um filme com algumas das sequências que foram filmadas, passando-se de Nova Iorque a Valparaíso, de Tóquio ao Cairo, de Paris à Beirute. $\mathrm{O}$ espetáculo, criado a partir destas sequências, inicia-se com o filme. Depois, entro em cena e interpreto o "ritornelo" ao vivo.

Um bailarino, depois uma bailarina e, em seguida, outra bailarina se juntam a mim, e a cada vez, nos oferecem o seu ritornelo. Eles tinham aprendido o meu ritornelo antes, quando dos ensaios, mas tornou-se totalmente superficial que ele fosse dançado tal-e-qual. Cada um o assumiu, transformando-o. O que os bailarinos criaram não poderia existir sem o que eu mesma havia criado; mas o inte-

\footnotetext{
${ }^{23}$ Este projeto é evocado no livro Les Danses du temps, op. cit. Ver «Instantané $2 »$.
} 
resse foi trabalhar sobre aquilo que o ritornelo poderia ser hoje. Não me parecia estimulante preservar estes ou aqueles movimentos, que haviam sido escolhidos em 1997, e que não teriam sido escolhidos atualmente. Seria mais favorável buscar o que teria motivado a estrutura e a modificar. Meu ritornelo é como uma assinatura de meu percurso, seria inútil dele tentar uma cópia exata. Parecia-nos mais oportuno ter esta sequência como base para construir as outras (Fontaine, 2015. p. 30,31). O espetáculo Millibar, une ritournelle chorégraphique conecta-se às variações do tempo, à duração, aos momentos duma grande atenção da dança de nossos corpos singulares.

Este mundo, a que o comparar? Na madrugada, Branco rastro de um barco à remo que se afasta. Manzei. Man yō shū - Século VIII ${ }^{24}$

\section{Referências}

ANDREWS, Jérôme. La danse profonde, de la carcasse à l'extase. Pantin: Centre National de la Danse, 2016, p. 85.

BARTHES, Roland. Roland Barthes par Roland Barthes. Paris: Seuil, 1975.

CUNNINGHAM, Merce. Entretien avec Lise Brunel. Chroniques de l'art vivant, n³4, novembre 1972, p. 26.

DELEUZE, Gilles. Deux régimes de fous. Paris: Les Éditions de minuit, 2003, p. 361.

FONTAINE, Geisha. Les danses du temps. Pantin: Centre National de la Danse, 2004, traduzido para o espanhol: Las danzas del tiempo, Buenos Aires: Centro Cultural de la Cooperación, 2012.

FONTAINE, Geisha. Millibar, une ritournelle chorégraphique, Repères - Cahiers de danse, \#35, avril 2015, p. 30,31.

FONTAINE, Geisha. Such a little thing. DanceHouse Diary, \#5, July-October 2013, Australia, p. 3-5.

FOUCAULT, Michel. Dits et Écrits. Paris: Gallimard, 1994, tomo IV, p. 580.

GENET, Jean. Lettres à Roger Blin. Paris: Gallimard,1966, p. 18. 
JAMESON, Fredric. Postmodernism, or The Cultural Logic of Late Capitalism, Durham: Duke University Press, 1991.

KANT. Critique de la raison purê. Paris: PUF, 1984, p. 408.

ROSA, Hartmut. Accélération, une critique sociale du temps. Paris: La Découverte, 2010.

SUQUET, Annie. L'éveil des modernités - une histoire culturelle de la danse. Pantin: Centre national de la danse.

VEYNE, Paul. Foucault, sa pensée, sa personne. Paris: Le livre de poche, 2010, p. 45.

YATES, Frances A., The Art of Memory, 1966.

ZEAMI. La tradition secrète du Nô. Paris: Gallimard, 1960. (Ver o livro 1: Remarques sur les exercices âge par âge. 